University of Wollongong

Research Online

Sydney Business School - Papers

Faculty of Business and Law

$1-1-2019$

\title{
Ability, motivation and opportunity: managerial coaching in practice
}

Grace McCarthy

University of Wollongong, gracemc@uow.edu.au

Julia Ahrens

EDHEC, jahrens@uow.edu.au

Follow this and additional works at: https://ro.uow.edu.au/gsbpapers

Part of the Business Commons

\section{Recommended Citation}

McCarthy, Grace and Ahrens, Julia: Ability, motivation and opportunity: managerial coaching in practice 2019, 1-22.

https://ro.uow.edu.au/gsbpapers/566

Research Online is the open access institutional repository for the University of Wollongong. For further information contact the UOW Library: research-pubs@uow.edu.au 


\title{
Ability, motivation and opportunity: managerial coaching in practice
}

\begin{abstract}
The practice of managerial coaching is increasing globally, although there is still comparatively little research into it. Using an online survey, we examined the practice of managerial coaching in Australian organisations through Appelbaum et al.'s Ability Motivation Opportunity framework. A thematic analysis of 580 responses revealed that managers regularly coached their own employees and were motivated by the outcomes they achieved through coaching. Emerging strongly from this research was the delight managers took in seeing their employees transform, as well as improved relationships and the (re-)building of trust. Furthermore, coaching resulted in employees becoming more innovative and ready for change. However, managers did not always have the opportunity to undertake coaching due to time constraints or their dual role as a coaching manager. We shed further light on the motivation of managers and we offer recommendations for HR departments seeking to foster managerial coaching in their organisations. The key takeaway is that managerial coaching is a powerful approach to leadership.

\section{Disciplines}

Business

Publication Details

McCarthy, G. \& Milner, J. (2019). Ability, motivation and opportunity: managerial coaching in practice. Asia Pacific Journal of Human Resources, Online First 1-22.
\end{abstract}




\title{
Ability, motivation and opportunity - managerial coaching in practice
}

McCarthy, G. University of Wollongong Australia

Milner, J. EDHEC, France

\begin{abstract}
The practice of managerial coaching is increasing globally, although there is still comparatively little research into it. Using an online survey, we examined the practice of managerial coaching in Australian organisations through the Ability Motivation Opportunity (AMO) (Appelbaum et al. 2000) framework. A thematic analysis of 580 responses revealed that managers regularly coached their own employees and were motivated by the outcomes they achieved through coaching. Emerging strongly from this research was the delight managers took in seeing their employees transform, as well as improved relationships and the (re-)building of trust. Furthermore, coaching resulted in employees becoming more innovative and ready for change. However managers did not always have the opportunity to undertake coaching due to time constraints or their dual role as a coaching manager. shed further light on the motivation of managers and we offer recommendations for HR departments seeking to foster managerial coaching in their organisations. The key takeaway is that managerial coaching is a powerful approach to leadership. We offer recommendations for HR managers to foster coaching in their organisations.
\end{abstract}

Keywords: leadership, managerial coaching, motivation, AMO, SDT, training

\section{Introduction}

Coaching by managers is rapidly increasing. $80 \%$ of UK managers say that they are expected by their organisations to coach their employees (CIPD 2015). This trend is seen in many parts of the world, e.g. China (Wang 2011), Korea (Kim 2014), Sweden (Rapp-Ricciardi, Garcia and Archer 2018), and Latvia and Lithuania (Rosha 2014). The increase can be attributed to three changes, according to a review by Fatien and Otter (2015, 26): firstly, a shift in the locus of responsibility for people development from a central Human Resources function to managers, secondly, a growing expectation that managers will facilitate learning and development, and thirdly, an increased focus on leadership culture. The responsibility of the Human Resources (HR) function has shifted to ensuring managers have the skills to support their employees, aligning employees with the values and strategy determined by the organisation (Bainbridge 2015).

Given this increased focus on coaching in the workplace, this paper seeks to make a contribution through understanding how and why managers coach their employees. Many of the theoretical advances in relation to our understanding of the coaching process and its outcomes have been made in the context of an external coach working with a person, often an executive, in an organisation. There has however been an increase in research related to internal coaching by managers and other internal 
coaches. A meta-analysis by Jones Wood and Guillaume (2016) found that while external and internal coaching both had a positive impact on learning and performance, the impact of internal coaching was greater. As outlined in the Method section below, this research analysed responses to an online survey of 580 Australian managers to examine managers' perceptions of coaching and the outcomes they thereby achieve, through the lens of the Ability Motivation Opportunity (AMO) framework developed by Appelbaum et al. (2000). According to Rayner and Morgan (2017), AMO is one of the most common conceptualisations of how human resource management practices influence performance, while Karam et al. (2017 p.110) describe AMO as the 'dominant emerging theoretical paradigm' for high performance HR practices. It is therefore useful in answering the three research questions of how managers enact coaching in the workplace, what motivates managers to coach and what influences managers to take advantage (or not) of opportunities for coaching in the workplace. These three questions address gaps identified in the Literature Review next.

\section{Literature Review}

When we talk about managers coaching their employees, it sometimes seems that coaching is conceptualised as a single action. Managerial coaching is defined as 'line managers who engage in coaching activities' (Beattie et al. 2014), where a coaching manager is 'a senior employee paid for by the employer to coach fellow employees' (Chong et al. 2016) and the activity is defined more broadly as 'helping employees to develop themselves for improving performance, elevating potential and increasing their vitality for the work they do’ (Ladyshewsky and Taplin 2018). These definitions however do not explain what a coaching manager does. Lawrence (2017 p.60) notes that while 'most definitions of managerial coaching emphasise the role of leader in facilitating the development of their direct reports. These definitions are less clear as to the nature of the coaching process'. Coaching requires a combination of skills, of which the most important according to McCarthy (2014) are observation, listening, questioning, goalsetting and feedback. While external coaches use the same skill set, their opportunities for observation are more limited than those of the coaching manager which may partly account for the better performance of internal coaches found by Jones, Woods and Guillaume (2016) in their meta analysis of coaching outcomes.

It should also be noted that it is possible for managers to implement the aforementioned skills without ever using the word 'coaching', adopting a conversational approach sometimes called informal or corridor coaching as described by Turner and McCarthy (2015) in their study of this form of coaching using interviews with 10 Australian managers. In her small scale phenomenological study of 6 sales managers in the UK, Dixey (2015) found that managers often engage in coaching conversations without necessarily regarding it as coaching and similarly employees may not realise they are being coached, which can distort efforts to measure the frequency of managerial coaching. Indeed similarities between effective leadership and managerial coaching have been identified by Hamlin Ellinger and Beattie (2006). 
Despite growing interest in managerial coaching, there is a lack of consensus in the literature about whether managers can or should coach. Some authors, e.g. Hunt and Weintraub (2016), Hicks and McCracken (2011) and Longenecker (2010) describe the positive role coaching managers can play. Whitmore $(2009,20)$ however warns that the manager 'traditionally holds the pay check, the key to promotion and the axe' and that this can inhibit the trust and safety required in a coaching relationship. Furthermore managers are seen as representatives of the company and the power imbalance inherent in this positional authority inhibits the effectiveness of the coaching process (Matthews 2010). Garvey, Stokes and Megginson $(2014,141)$ stress that line manager power can lead to collusion between manager and coachee, or to the coachee being less open and thereby limiting the extent to which coaching can succeed. It may be that some of these arguments are semantic, that authors like Hunt and Weintraub (2016) are talking about managers deploying coaching skills, rather than replicating the role of the external executive coach. Clutterbuck, Megginson and Bajer (2016) suggest that there are considerable benefits when managers integrate a coaching approach into their daily routine, whereas they believe it is both unrealistic and undesirable for managers to be expected to adopt the role of a professional coach.

Although coaching managers use similar skills to those of the external coach, they may encounter different challenges, e.g. assuring confidentiality, perceptions of potential bias and the multiple roles of the manager (Bresser 2011 ; Ferrar 2006 ; Schalk and Landeta 2017 ; McCarthy and Ahrens 2011). Noting the importance of intent, Hunt and Weintraub (2016) claim that if managers are genuinely trying to support their employees, then sufficient trust will emerge for coaching to take place. A recent review of the literature relating to managerial coaching (Lawrence 2017) found that to coach one's own employees requires a specific mindset and thinking style as well as a different set of skills to those of the external coach, viz. relationship building, feedback, ability to switch from coaching to other forms of interaction and team coaching. Given these differences, Lawrence argues that the managerial coach requires no less skill than the external coach but rather different skills.

There is to date little empirical research that examines how managers put coaching into practice in the workplace. This gap in the literature leads to the first research question:

\section{Research Question 1: How do managers enact coaching in the workplace?}

\section{Motivation to Coach}

Empirical evidence of the benefits of managerial coaching has been reported by many authors, e.g. recent studies by Lin, Lin and Chang (2017), Pousa et al. (2017) and Özduran and Tanova (2017). In their study of 119 supervisors acting as coaches in a Taiwanese refinery, Lin, Lin and Chang (2017) highlighted the benefits of managerial coaching on employee performance, when supervisors adopted a promotion/ developmental orientation. Pousa et al. (2017) found in their study of 318 advisers in two Canadian banks that managerial coaching contributed to employee performance at all stages of an employee's career, not only at the early stages as might have been thought. Özduran and Tanova 
(2017) surveyed 40 managers and 176 employees in 12 hotels in Cyprus. They report that where there is a low procedural justice climate, effective coaching enhances the organisational citizenship behaviours of employees. In contrast, where procedural justice climate is high, organisational citizenship behaviours are also high, and coaching has less impact. A summary of studies of benefits associated with managerial coaching is provided in Table 1.

Table 1 Approx. here.

The outcomes of managerial coaching listed in Table 1 are clearly of interest to HR departments as they demonstrate the positive impact managers can have on employee performance and engagement, even in less than ideal contexts such as the Özduran and Tanova (2017) study in Cyprus cited above where coaching compensated for a low procedural justice climate. What we do not know from the literature is whether managers themselves see benefits from coaching and are convinced of its merits or whether they only do it because it is company policy. There have been calls for further investigation into the benefits that managers themselves receive from serving as coaches (Beattie et al. 2014, 197). Understanding what motivates managers to coach could be significant for HR managers seeking to obtain the benefits listed in Table 1 . This leads to the second research question:

Research Question 2: What motivates managers to implement coaching in the workplace?

\section{Opportunities for managers to coach}

Notwithstanding the benefits associated with managerial coaching, deployment of the practice within organisations is inconsistent. This can lead to problems according to previous researchers such as Turner (2010) who noted that an organic/emergent approach can lead to dysfunctional behaviours, while a structured centralised approach could curtail organic developments through a lack of flexibility. There is no coaching without an opportunity, write Hunt and Weintraub (2016, 34), arguing that 'it is the opportunity that drives the learning'. Unlike external coaches who only see a snapshot of an employee periodically, managers see employees in their everyday work role and can give prompt targeted feedback (Hunt and Weintraub 2016 ; McCarthy and Milner 2013). Nonetheless managers can be hesitant about commencing a coaching conversation, fearing, for example, that an employee may react negatively to the feedback (Turner and McCarthy 2015). Therefore, even when managers have the opportunity to coach, they may not take advantage of that opportunity. The most common inhibitor mentioned in the literature is time, e.g. McLean (2005) and Ellinger, Hamlin and Beattie (2008). It would be useful to identify other issues that, if addressed, would enable a more consistent deployment of the coaching practices resulting in the positive organisational outcomes listed above. This leads to the third research question:

Research Question 3: What influences managers to take advantage (or not) of opportunities for coaching in the workplace?

\section{Method}


To obtain in-depth insights from a large number of coaching managers, we chose to deploy an online survey with free text responses as this allowed us to get views from more people than we could have done through interviews. We sent a questionnaire to a mailing list of 9053 general managers and human resource managers in Australian organisations employing at least 200 people as organisations of this size were considered more likely to have coaching practices in place. Invalid email addresses reduced the number of recipients to 8834 , of whom (after a reminder was sent) 580 or $6.6 \%$ completed the survey. This is a very low response rate, however 580 responses from general managers and HR managers provided rich details and examples in extensive free text responses, thereby illuminating the experience of managers adopting a coaching approach.

We asked some closed questions to find out how often managers coached and whom they coached. We also asked several open questions such as 'As a manager, have you experienced any benefits from adopting a coaching style?' and 'Have you experienced any difficulties with coaching as a manager?' A full list of questions is provided in the Appendix. The online survey results were downloaded into both Excel and nVivo. Concepts were identified initially by conducting a word frequency count, including stem words (e.g. engaged, engaging or engagement) and synonyms of such words. The free text responses were initially coded in nVivo using a thematic analysis approach. Coding, according to Saldaña $(2009,10)$ allows the researcher 'to organise and group similarly coded data into categories or 'families' because they share some characteristic - the beginning of a pattern'. While primarily an inductive approach analysing themes in the data, thematic analysis is rarely purely inductive or purely deductive (Braun and Clarke 2012, 58). Concepts found in the literature review were also searched for using the text search function, to ensure that important concepts were not ignored, even if they did not occur frequently. The context and attributes of each occurrence were examined, e.g. positive, negative, and whether the respondent classed it as important. For example, when the term 'confidentiality' appeared in managers' responses, it usually related to a breach of trust, and the surrounding text indicated a major negative impact, as indicated by the use of upper case letters by the respondents. This approach is consistent with Gioia, Corley and Hamilton (2013) who recommend the first order of analysis be informant-centric, leading in this study to the identification of the joy experienced by the coaching manager. Each node (set of references to a particular theme) was then reviewed, clustered with others where appropriate, and nuances teased out. Connections between concepts were also noted, e.g. 'engagement' was often found in the same phrase as 'productivity'. We then undertook a second order analysis, and found the themes clustered naturally within the AMO framework as can be seen in the findings below. This approach, where we first asked open coaching style questions, the answers to which we then coded to themes, and only then clustered the themes within the AMO framework, avoided forcing the data into a pre-determined framework.

\section{Findings}

\section{Managers regularly use coaching with their direct employees}


94\% of respondents coached their direct reports. As can be seen in Table 2, 73\% of respondents coached their employees at least once a week. When asked about coaching skills, over $90 \%$ of respondents said they used active listening and questioning. Managers were clear that coaching was more about listening and asking, rather than telling people what to do:

'The questioning and leading style people appreciate, it is not a lecture. They appreciate the discussion and the performance benefits are more permanent, you can change people.'

'I ask a lot of questions from my team and especially leaders in my organisation. The benefit is they engage with the matter/problem can talk through it, understand it and are more likely to be open to a solution.'

'The key elements of coaching are the active listening and open style questions allowing people to think through issues themselves. Most people generally respond positively in conversations to this technique so it promotes relationships.'

$90 \%$ of respondents used a coaching approach to give feedback:

'I believe it delivers an ongoing version of 360 degree feedback which is a far better method than an annual performance appraisal.'

' Enables me to provide feedback to and drive change with peers that are older and more experienced than me in a non-confrontational, solutions focused way.'

A smaller proportion but still a majority of managers (78\%) used coaching to set goals, perhaps because the organisational goals were already set, and so goal setting for these managers was more often about developmental goals.

'Employees feel very empowered when they identify solutions and achieve goals.'

'I have used coaching to achieve specific development goals and personal transformation in those I have coached.'

The responses indicate that not only did managers deploy coaching skills, they also achieved positive outcomes, e.g. listening promoted better quality relationships and questioning led to people being more open to a solution. These outcomes imply that managers have sufficient coaching ability to achieve their intent.

Most respondents also acknowledged that they had experienced some difficulties in coaching, however these did not relate to their level of coaching skills but rather to lack of time (as will be explored under Opportunity below) or issues relating to confidentiality, power or the dual role of manager and coach, as indicated in the quotes below:

'There are boundary issues about power and confidentiality that need to be negotiated.' 'It's difficult to ignore the overriding power imbalance that exists between managers and employees.' Managers chose when to use a coaching approach:

'I don't automatically slip into a coaching role, so you are thinking through what you need to do, how will it be perceived by the person you want to coach.' 
'The coaching is relatively straightforward. The challenge is in switching roles and ensuring the staff member has appropriate expectations.'

Many participants articulated the need to delegate and empower their teams:

'It is difficult to give up this power base and be confident that your staff have the solutions.'

'You need to build confidence that they can at some stage stop relying on the coach for advice and make decisions based on their acquired learning.'

A challenge that emerged was the importance of creating equal opportunities for all employees to be coached:

'If individuals [...] seem to be favoured over others then this can create disharmony and feelings of cronyism. [...] there needs to be transparency and opportunities for all who wish to be coached to some degree.

Managers also argued that it is difficult, perhaps impossible, for some managers to adopt a coaching approach. They associated lack of skill particularly with managers who found it difficult to delegate, or who believed that they should have all the answers, noting that it is unlikely that such managers would give up their power and trust employees to come up with solutions. Participants also noted the possibility of employees becoming dependent on their coaching manager, which could make employees reluctant to take ownership.

Coaching managers need skills to build employees' confidence in their own decision-making and to avoid coaching leading to perceptions of favouritism. However participants had received only limited training in coaching, and the training they had received was generic rather than tailored to managerial coaching.

\section{Managers have the motivation to coach}

Seeing the growth and career development of their employees was a source of great personal satisfaction for participants in this study. Of particular note was the strong language used by participants, e.g. 'joy’, 'revelation’ and 'happiness’. For example, managers said 'To see shy unsure individuals develop into assured professional team leaders and managers is a joy to see.'

'I have achieved great pleasure in seeing the development of both individuals and teams that I have coached and seen them progress to assured and professional employees.'

'Overall feeling of happiness when I see the positive changes that they are making and the positive impact my coaching is having on such a large influential group of our business.'

'Whilst I knew in theory that coaching is effective, it was a revelation to me effective the investment in coaching as a manager could be.'

'This indicates a level of personal commitment beyond compliance with a company policy requiring 
managers to coach. Managers also reflected on their own growth and how they became better managers through coaching:

'I have learned about my strengths and weaknesses, have improved my active listening, been able to delegate more when people are confident in their own skills.'

'I have learnt lots about myself, the organisation I work with or for, and about how I can do my job better.'

'It increases your confidence as a manager and makes it easy to do your job.'

Managers were motivated by seeing the outcomes of the coaching process, such as empowerment, alignment, and readiness for change. Empowerment was possible because employees were clear on goals and expectations, according to many participants. Coaching helped employees see how their work contributed to the organisational goals and they could then decide how best to perform their work, e.g.

'Employees are empowered to make their own decisions; they learn and are more willing to make mistakes because they know they are supported.'

'Employees feel very empowered when they identify solutions and achieve goals. They also have greater ownership and commitment to actions that they have identified they need to take.'

Alignment helped employees feel a sense of identity, belonging, ownership and ability to make a contribution. Alignment, empowerment and motivation were often linked in managers' responses, e.g.

'Staff are clearer on your views/strategies and beliefs on how the business should run. Staff can make their own decision knowing that it is aligned with the overarching goals of the business.'

Participants stated that coaching resulted in employees becoming more engaged:

'You can generate a higher level of engagement and commitment because the individual being coached can experience first-hand your personal commitment to their development.'

'Increases engagement, passion and enthusiasm at work which drives better results and also often positively affects home life.'

'A lift in team productivity, commitment and engagement as employees see their achievements acknowledged, views respected and listened to and involvement rewarded.'

Coaching also resulted in employees being better able to engage with new challenges, and indeed to become change agents themselves:

'It provides a supportive environment for employees and facilitates knowledge sharing, continual improvement \& change.'

'They are employees who become your change champions and then looked up to by their peers becoming leaders in their own right.' 
Participants noted that the employees they coached felt supported, able to cope with change, more flexible in their thinking, innovative, willing to take risks and to take the initiative:

'Individuals have improved their ability to think laterally and see that it's important to continually be open to learning.'

'Creates a competitive edge of learning agility and enthusiasm to approach new challenges rather than seek a stable low risk existence.

'I have witnessed light bulb moments which have led to whole strategies being revised and invigorated as a result of coaching interventions.'

Participants suggested that because employees understood the business better, they were more interested in their work, better able to take appropriate decisions and more motivated to perform: 'Some of the staff are pleased that their manager takes the time to listen to them. This can only be good for morale and feeling wanted in the team.'

'They enjoy working here - feel that their opinion is valued and are not afraid to say what they feel or think.'

'Improvement in the relationship is more likely to encourage an employee to discuss issues that may be affecting their performance.'

These outcomes reinforced the manager's motivation to coach and his/her engagement and commitment to the organisation. It was clear from many responses that coaching was not only an intellectual endeavour, but involved caring interpersonal relationships, with staff enjoying their managers' attention regardless of the content of the conversation:

'Staff who believe their managers and organisations care about them by investing their time in coaching them are naturally more positive, happier whilst working, they are great team players, their skills improve, they get promoted and most importantly this flows onto how your customers are treated, treat staff well and they treat your customers well. Your business then flourishes.' 'If you stress you are doing the coaching because you care and want to see continuous improvement then this employee will became one of your best, they become engaged, happier both at home and work, their health improves, they get promoted, earn more money, there's too many benefits to list.'

Many participants identified engagement as an outcome of coaching, often linking engagement with improvements in performance and productivity. They felt that improved relationships resulted not only from managers spending time with and listening to their employees but also from their being genuinely interested in the growth and development of their employees:

'You can generate a higher level of engagement and commitment because the individual being coached can experience first-hand your personal commitment to their development.'

In some organisations, it took time for employees to accept that coaching was not being used as a disciplinary tool but intended to help them grow and develop. The positive relationships developed 
through coaching developed trust, in some cases even re-building trust that had been lost through previous bad experiences:

'When you coach people rather than command people you almost always win their hearts and minds, so loyalty, trust and confidence are built.'

'The spin off from being a coaching manager verses being a managing manager is quite profound in the trust developed and overall morale.'

'Allowing people to make mistakes and learn from them, take ownership creates a great relationship of mutual trust and respect.'

'Staff members who have previous bad work experiences and therefore lost trust in management have regained trust.'

\section{Time and context influence whether or how managers take advantages of opportunities to coach}

Given their positive experiences of coaching, it is salutary to note that many participants emphasised that coaching is by no means a miracle cure. A common complaint related to lack of time or a lack of appreciation of coaching within their organisations which could deter managers from taking the opportunity to coach:

'Sometimes it takes a long time to develop a trusting relationship and create a foundation to do good coaching work.'

'Takes a while for the coachee to recognise I am there to be an honest helper.'

'Time is always a factor and this can affect expectations of both the coach and the employee.

Dissatisfaction is quick to set in if expectations are not met or controlled so that both parties appreciate what is expected of them.'

'Coaching is time dependent and senior management are not tolerant of this.'

'You don't necessarily get recognised by the organisation for coaching, but the organisation does benefit in the growth of the individual / team.'

On the other hand, many also stated that coaching saved them time in the long run:

'I now get solutions brought to me rather than being the solution provider. This has given me more time to lead and develop my staff.'

'Employees begin to mirror my leadership style and decision making thought process; I save time not having to provide decision making at every step.'

Furthermore, there were situations which managers did not regard as appropriate for coaching, such as downsizing or turnaround situations:

'Where there is an urgent deadline or immediate and decisive action is required to protect life, property or reputation, coaching may have to occur with hindsight (what did you learn from that?) rather than in the moment (what do you think we should do?).

'The only time I do not favour coaching is when we are under extremely tight timeframes, when immediate results are expected or when change is imperative.' 
Flexibility in choosing when to apply a coaching approach and when to choose mentoring or a more directive style of leadership was seen as important:

'If we are always in coaching mode, or always non-directive, we lose some credibility and 'leadership'. We need to be flexible in approach and use what is needed and when it is needed.' Taking advantage of the opportunity also meant assessing the willingness of the employee to be coached. Some managers reported that their employees preferred being told what to do, although the majority said that employees valued a coaching approach. The actual approach varied, e.g. some managers used a more informal coaching approach with employees at lower levels in the organisation:

'Coaching techniques can be used for everyone from apprentices to Executives and CEO's. It takes a bit more education at the lower levels to get buy in from individuals as they do like to be told what to do. At times I use informal coaching techniques at these levels.'

\section{Discussion}

As reported above, coaching managers use generic coaching skills such as listening and questioning. However they also need skills in empowering their employees, managing confidentiality, knowing when to adopt a coaching approach, how to avoid employees becoming dependent and how to avoid perceptions of favouritism. This confirms that the skills required of a coaching manager are somewhat different from those of the external coach as suggested by Lawrence (2017).

This study provides further examples of the benefits identified by previous research, summarised in Table 1, e.g. empowerment and alignment. The quotes by participants in this research enrich the understanding of how these outcomes are experienced by managers and crucially, how passionate managers are about coaching because of these outcomes. Coaching in this study emerges not simply as an intellectual or task-oriented approach but is transformational, generating growth in employees and in the managers themselves.

The findings further support Bond and Seneque's $(2013,68)$ view of coaching as 'Developing the individual/team's capacity to identify and find solutions to their own problem situations in the context of the strategic intent and goals of the broader "system".'

A new insight in this study was that managerial coaching enhances employees' willingness to take risks, try new things, to cope with change and indeed to become agents of change themselves. Previous research had identified that readiness for change was enhanced by external coaching (Du Toit 2007 ; Stober 2008), and internal coaching of people who were not direct reports (Rock and Donde 2008). The attributes identified here such as willingness to take risks and try new things are attributes that help employees to embrace change and innovation, both of which are highly valued by organisations in today's fast moving world. 


\section{Implications for Theory}

In addition to the intellectual problem-solving aspect of coaching, many respondents stressed the positive impact of coaching on relationships. Managers are motivated not only by achieving organisational benefits but also the intense personal satisfaction they experience from coaching and seeing their employees thrive. This adds to our understanding of how managerial coaching is experienced by the manager and the importance of the managers' relationship with their employees, which may be helpful to HR departments seeking to encourage managers to adopt a coaching approach.

The strong response regarding relationships suggests that the Motivation element of the AMO framework might be illuminated through Self-Determination Theory (SDT). Self-Determination Theory (SDT) is a theory of motivation developed by Deci et al. over the past 4 decades, e.g. Deci (1975), Ryan and Deci (2000) and Gagne and Deci (2005). STD has been identified as a useful framework to adopt in encouraging line managers to adopt HR practices in a study of over 700 employees in Norway (Kuvaas, Dysvik and Buch 2014). As a theory of motivation, SDT fits naturally within the AMO framework. It comprises three elements, competence (which relates to Ability in the AMO framework and has already been discussed in relation to skills), social relatedness and autonomy. SDT has previously been used in coaching research but in connection with the person being coached rather than the person doing the coaching. Examples include Spence and Deci (2013) and Gabriel, Moran and Gregory (2014). 'Social relatedness' in SDT links with the coaching relationship long recognised as a critical success factor in coaching, e.g. Bluckert (2005), Palmer and McDowall (2010). Managers in our study see coaching as a way of enacting empowerment, warning that this is difficult for managers who have a 'command and control' style of leadership. This conceptualisation is consistent with Clutterbuck, Megginson and Bajer (2016) who also concluded that managers used to 'command and control' struggle with adopting a coaching approach.

The third element of SDT, autonomy, was also identified as important by the respondents in this study who warned against enforcing a requirement to coach. The increasing evidence of the benefits attainable through coaching leads some organisations to mandate a coaching approach. However the participants in this study warned against imposing a blanket requirement, stressing that not all managers have the inclination or skill to coach. This finding supports some previous research, e.g. Anderson, Rayner and Schyns $(2009,12)$ argued that a 'requirement for all managers to fulfil a 'manager as coach' role may be problematic'. The study also confirmed that lack of time may limit the opportunity for managers to coach (Beattie et al. 2014) . Furthermore there are times when coaching is not the appropriate approach. Managers want the flexibility to choose the right situations in which to use coaching and when to use other approaches.

Although Gould-Williams (2016) suggests that AMO is adopted by managers adopting a high performance approach who are primarily interested in improving performance, while SelfDetermination Theory (SDT) underpins a high involvement approach where managers focus on the 
processes leading to improved outcomes, we suggest that both may be useful in managerial coaching. Figure 1 shows a combined AMO-SDT framework.

Figure 1 approx. here

This study shows that many managers regularly coach their employees and that they achieve positive outcomes from doing so, indicating they have the requisite ability. In addition to outcomes for employees and the managers' own personal satisfaction at seeing the transformation in their employees as a result of coaching, the outcomes reported include organisational outcomes such as enhanced productivity. Figure 2 proposes a model whereby organisational outcomes are achieved through managerial coaching.

Figure 2 approx. here.

Figure 2 includes the crucial role HR Managers can play in educating managers and executives about the value of a coaching approach (motivation), training managers in when and how to use a coaching approach (ability/competence), facilitating peer support (social relatedness) and allowing managers to determine when coaching is the right approach to use (autonomy) in order to take advantage of situations that provide the context for a coaching conversation (opportunity). Implementation of HR practices is variable, according to Van Waeyenberg and Decramer (2018), because it depends on line managers having the ability, motivation and opportunity to implement. Kuvaas, Dysvik and Buch (2014) note the tension between aiming for consistency of implementation of HR practices and flexibility allowing managers autonomy. They propose training as a better way to improve consistency than increased formality or standardisation. Milner, McCarthy and Milner (2018) emphasise the importance of tailoring coaching training to the needs of the coaching manager. We suggest that providing dedicated managerial coaching training will be motivating for managers providing a social context and a common language with peers, equipping managers with the skills not only to coach but also to identify situations in which coaching is likely to be the most effective intervention, which coaching approach to adopt in different situations, how to set up the relationship for success, and how to avoid perceptions of favouritism or employees becoming dependent. This approach is in line with recommendations by Gollan, Kalfa and Xu (2015) who advocate that HR managers should focus on supporting line managers to ensure HR practices are implemented consistently and equitably, and with Trullen et al. (2016) who stress that HR managers can positively influence the implementation of HR practices through initiatives that enhance line managers' ability, motivation and opportunity. Hitherto the coaching literature has paid scant attention to the role of the HR department in championing managerial coaching, focusing more on managers' coaching skills and the definitions and effectiveness of managerial coaching, e.g. reviews by Gormley and Van Nieuwenburgh (2014) and Lawrence (2017).

\section{Implications for Practice}


All three elements of the AMO framework were evident in the responses managers provided. Given previous research indicating that managers are more likely to implement HR practices where these elements are present, an understanding of how these elements are experienced by coaching managers is helpful to HR departments seeking to promote managerial coaching. By combining AMO and SDT and applying the revised framework on an on-going basis, HR managers increase the likelihood of a desired HR practice, in this case coaching, being adopted by managers in order to achieve the benefits identified in this study and in previous studies cited earlier. While it is tempting to think of AMO as a linear process where motivated managers are first trained and then apply their skills when they see an opportunity, we argue that Ability, Motivation and Opportunity must each be reinforced on an ongoing basis. Hence we provide suggestions in Table 3 for both an initial and an on-going process. Table 3Approx. here

In compiling these recommendations we have addressed not only Ability and Opportunity, but the additional elements of Motivation in SDT, viz. autonomy and social relatedness, in order to provide a strong foundation for managerial coaching. Our recommendations address the difficulties identified by managers in this study and also the prerequisites for establishing a coaching culture derived from a literature review by Gormley and Van Nieuwerburgh (2014), viz. promoting coaching throughout the organisation, role modelling by leaders and integrating coaching into organisational systems. Rather than mandating a coaching approach, we propose that HR departments allow autonomy and motivate managers to coach by providing relevant and credible evidence of positive outcomes such as those described by managers in this study. Explicit communication about the purpose of coaching and the time required for implementation could reduce unrealistic expectations of both senior managers and employees.

\section{Limitations and further research}

This study has several limitations in addition to the geographic limitation of the survey being conducted in Australia and the non-random nature of the sample meaning the results cannot be generalised. The managers who took the time to complete the survey were interested in coaching, hence there is likely to be a positive bias. These managers may also be more skilled in coaching, more motivated to coach and more likely to take the opportunity to coach than their peers and hence more likely to achieve the benefits they cite than those with less skill or less motivation.

This study relied on self-reports by managers and the outcomes reported by managers reported have not been verified. Further research could explore this further, taking account of the perspective of the employees being coached and evaluating the level of coaching skill of the managers as well as demographic factors such as gender, age and tenure. The additional findings relating to coaching enhancing employees' readiness for change and the personal satisfaction managers gain through coaching could also be further investigated. Further research is also needed to test the proposed model in Figure 2. Ideally this would be done as a multi-level longitudinal study to evaluate whether the benefits achieved through managerial coaching are achieved at the organisational level when 
managerial coaching is widely implemented across an organisation. Researchers could also evaluate the effectiveness of adopting AMO or SDT separately or combining the two frameworks as suggested here.

\section{Conclusion}

The AMO framework enhanced by SDT was useful in examining the data for evidence of the managers' coaching ability, their motivation to coach, and whether or not they had the opportunity to coach. The online survey approach adopted was successful in eliciting the view of a large number of General Managers and Human Resource Managers whose extensive free text responses expressed their passion for the power of coaching.

This study demonstrates the power of managerial coaching and identified two outcomes not previously found in the literature: the strong personal satisfaction, motivation and enhanced relationships of managers adopting a coaching approach and the ability of coaching to enhance employee readiness for change. To our knowledge, this is the first paper to incorporate SDT with AMO for the purpose of promoting managerial coaching which provides additional insights underpinning our recommendations for HR managers.

\section{Key points}

1. Coaching by managers is increasing.

2. Coaching managers report benefits including personal satisfaction, employee transformation, and positive organisational outcomes.

3. Managers have the ability and the motivation to coach but not always the opportunity.

4. Specific training and on-going support for managers are recommended for HR managers seeking to encourage the adoption of managerial coaching.

Acknowledgements: We sincerely acknowledge the constructive reviews by the editor and reviewers which have greatly strengthened this paper. 
Table 1 Benefits of Managerial Coaching

\begin{tabular}{|c|c|c|c|}
\hline Benefit & Findings & Method & Context \\
\hline \multicolumn{4}{|c|}{ Empowerment, Learning and Development } \\
\hline Ellinger (2003) & $\begin{array}{l}\text { Empowerment and } \\
\text { learning }\end{array}$ & $\begin{array}{l}\text { Critical Incident } \\
\text { Technique interviews } \\
\text { (CIT) }\end{array}$ & 12 managers in US \\
\hline $\begin{array}{l}\text { Huang and Hsieh } \\
\text { (2015) }\end{array}$ & Empowerment & Survey & $\begin{array}{l}324 \text { employees in hotels } \\
\text { in Taiwan }\end{array}$ \\
\hline $\begin{array}{l}\text { Wakkee et al. } \\
\text { (2010) }\end{array}$ & $\begin{array}{l}\text { Improved } \\
\text { employee } \\
\text { entrepreneurial } \\
\text { behaviour }\end{array}$ & Survey & $\begin{array}{l}353 \text { employees in Dutch } \\
\text { multinational }\end{array}$ \\
\hline Wheeler (2011) & Alignment & Case study & Tourism company in UK \\
\hline \multicolumn{4}{|l|}{ Performance } \\
\hline $\begin{array}{l}\text { Agarwal et al. } \\
\text { (Agarwal, Angst and } \\
\text { Magni 2009) }\end{array}$ & $\begin{array}{l}\text { Improved } \\
\text { employee } \\
\text { performance }\end{array}$ & Survey & $\begin{array}{l}421 \text { employees in } \\
\text { multinational company in } \\
\text { US }\end{array}$ \\
\hline $\begin{array}{l}\text { Dello Russo et al. } \\
\text { (2017) }\end{array}$ & $\begin{array}{l}\text { Improved } \\
\text { performance } \\
\text { management }\end{array}$ & Survey & $\begin{array}{l}591 \text { employees, public } \\
\text { and private sector, Italy }\end{array}$ \\
\hline $\begin{array}{l}\text { Ellinger et al. (2003) } \\
\text { Ellinger (2003) }\end{array}$ & $\begin{array}{l}\text { Improved } \\
\text { employee } \\
\text { performance }\end{array}$ & $\begin{array}{l}\text { Survey } \\
\text { Critical Incident } \\
\text { Technique (CIT) } \\
\text { interviews }\end{array}$ & $\begin{array}{l}505 \text { participants in } \\
\text { warehouses in US for } \\
\text { survey } \\
12 \text { managers for CIT in } \\
\text { US }\end{array}$ \\
\hline $\begin{array}{l}\text { Huang and Hsieh } \\
\text { (2015) }\end{array}$ & $\begin{array}{l}\text { Improved } \\
\text { employee } \\
\text { performance }\end{array}$ & Survey & $\begin{array}{l}324 \text { employees in hotels } \\
\text { in Taiwan }\end{array}$ \\
\hline
\end{tabular}


Table 2 Frequency of Managerial Coaching

\begin{tabular}{|l|c|}
\hline How often do you coach your employees? & $\begin{array}{c}\text { Response } \\
\text { Percent }\end{array}$ \\
\hline Daily & $27.0 \%$ \\
\hline More than once a week but not daily & $35.1 \%$ \\
\hline Once a week & $11.0 \%$ \\
\hline Less than once a week and more than once a month & $19.3 \%$ \\
\hline Once a month or less & $7.7 \%$ \\
\hline
\end{tabular}


Table 3 Recommendations for HR Managers Implementing Managerial Coaching

\begin{tabular}{|c|c|c|}
\hline & Initial Stage & On-going \\
\hline Ability & $\begin{array}{l}\text { Provide specific managerial coaching } \\
\text { training to establish competence and } \\
\text { confidence enabling managers to } \\
\text { identify and take advantage of coaching } \\
\text { opportunities. }\end{array}$ & $\begin{array}{l}\text { Organise peer support, provide advice, } \\
\text { updates on managerial coaching skills } \\
\text { and tackling specific challenges and } \\
\text { contexts. } \\
\text { Provide coaching training for newly } \\
\text { promoted managers and new hires. }\end{array}$ \\
\hline Motivation & $\begin{array}{l}\text { Encourage senior managers to role } \\
\text { model and speak positively about } \\
\text { coaching. } \\
\text { Share benefits of coaching by credible } \\
\text { managers. } \\
\text { Aim to persuade managers rather than } \\
\text { dictate their approach (allow } \\
\text { Autonomy). }\end{array}$ & $\begin{array}{l}\text { Organise peer support to provide fresh } \\
\text { examples of benefits (Social } \\
\text { Relatedness). } \\
\text { Encourage senior managers to speak } \\
\text { positively about the examples shared. } \\
\text { Provide recognition for managers } \\
\text { adopting a coaching approach. }\end{array}$ \\
\hline Opportunity & $\begin{array}{l}\text { Encourage managers to take } \\
\text { opportunities to coach. } \\
\text { Provide awareness training to all } \\
\text { employees so there is a shared } \\
\text { expectation of what coaching is, how it } \\
\text { will be used and what can be expected. } \\
\text { This will enable managers to take } \\
\text { advantage of opportunities. } \\
\text { Link coaching with the organisation's } \\
\text { values, and with expectations of } \\
\text { managers to encourage learning and } \\
\text { development. }\end{array}$ & $\begin{array}{l}\text { Include coaching awareness in induction } \\
\text { training for new employees. } \\
\text { Link coaching with the HR strategy, } \\
\text { career development process and related } \\
\text { systems so that it is easier for managers } \\
\text { to take advantage of opportunities to } \\
\text { coach. }\end{array}$ \\
\hline
\end{tabular}


Figure 1 AMO Framework Incorporating SDT

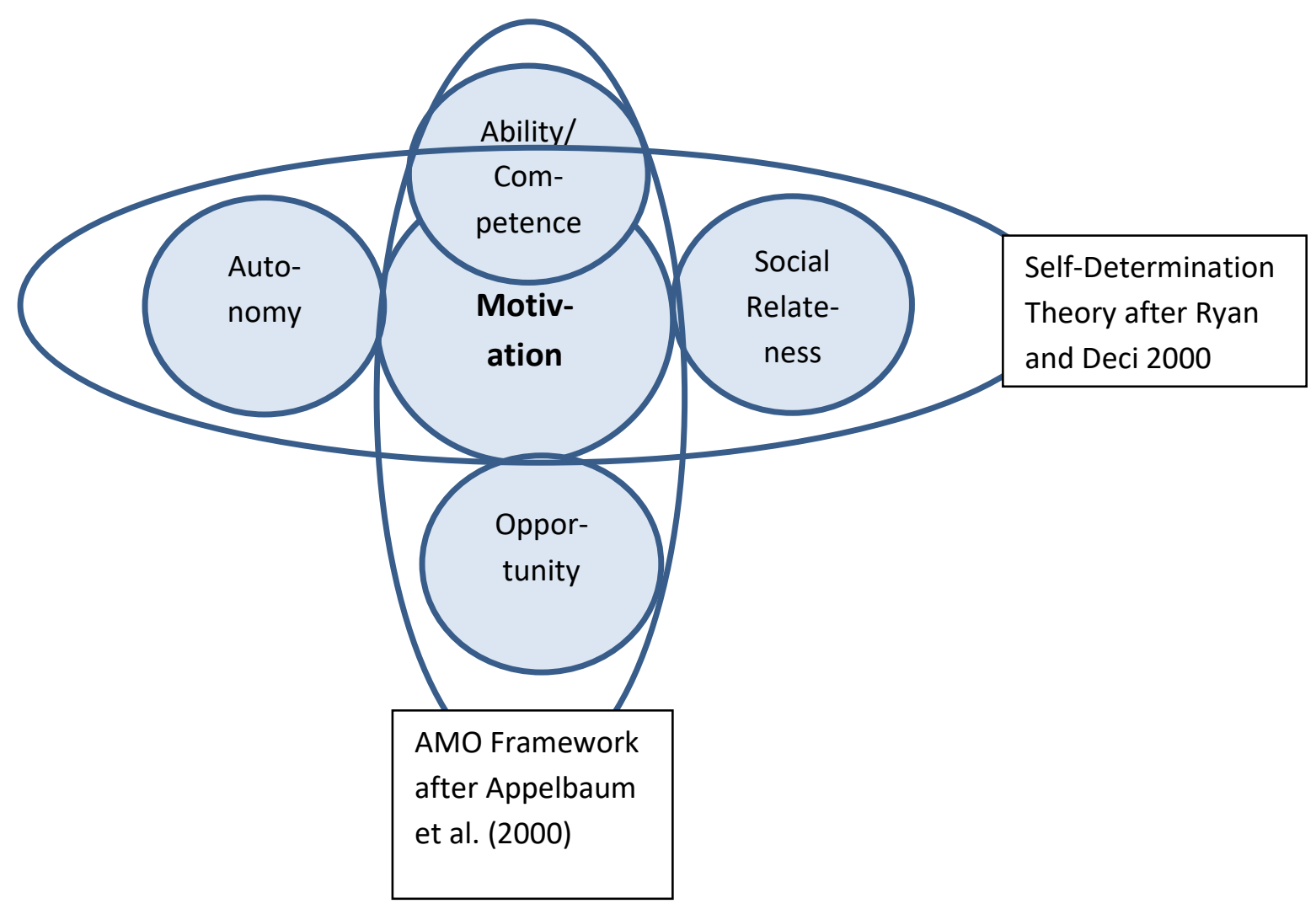


Figure 2 Outcomes of Managerial Coaching

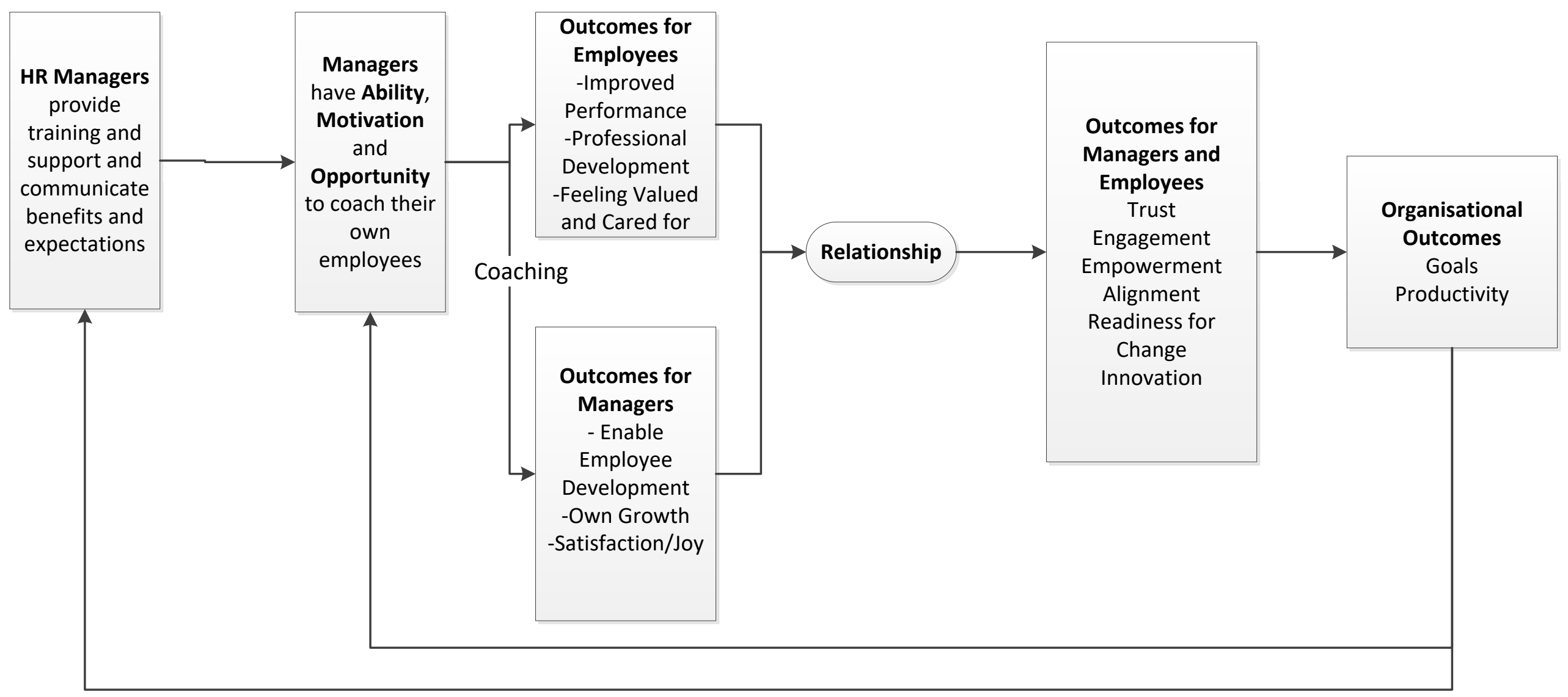




\section{References}

Agarwal R, CM Angst and M Magni (2009) The performance effects of coaching: A multilevel analysis using hierarchical linear modeling. The International Journal of Human Resource Management 20: 2110-2134.

Anderson V, C Rayner and B Schyns. (2009) Coaching at the sharp end: the role of line managers in coaching at work. CIPD, London.

Appelbaum E, T Bailey, P Berg, et al. (2000) Manufacturing competitive advantage: The effects of high performance work systems on plant performance and company outcomes, Cornell University Press, NY.

Bainbridge H (2015) Devolving people management to the line: How different rationales for devolution influence people management effectiveness. Personnel Review 44: 847-865.

Beattie RS, S Kim, MS Hagen, et al. (2014) Managerial Coaching: A Review of the Empirical Literature and Development of a Model to Guide Future Practice. Advances in Developing Human Resources 16: 184-201.

Bluckert P (2005) Critical factors in executive coaching - the coaching relationship. Industrial and Commercial Training 37: 336-340.

Bond $C$ and $M$ Seneque (2013) Conceptualizing coaching as an approach to management and organizational development Journal of Management Development 32: 57-72.

Bresser F (2011) Suits you. Coaching at Work 6: 42-45.

Chong CW, CW Chong, YY Yuen, et al. (2016) Managerial coaches, are they ready? The case of Malaysian telecommunications industry. The Learning Organization 23: 121-140.

CIPD. (2015) 17th Annual Learning and Development Survey. CIPD, London.

Clutterbuck D, D Megginson and A Bajer. (2016) Building and Sustaining a Coaching Culture, Kogan Page Publishers.

Deci EL. (1975) Intrinsic motivation, Plenum Press, New York.

Dello Russo S, M Miraglia and L Borgogni (2017) Reducing Organizational Politics in Performance Appraisal: The Role of Coaching Leaders for Age-Diverse Employees. Human Resource Management 56: 769-783.

Dixey A (2015) Managerial coaching: A formal process or a daily conversation? International Journal of Evidence Based Coaching and Mentoring: 77.

Du Toit A (2007) Making sense through coaching. Journal of Management Development 26: 282-291.

Ellinger AD (2003) Antecedents and Consequences of Coaching Behavior. Performance Improvement Quarterly 16: 5-28.

Ellinger AD, AE Ellinger and SB Keller (2003) Supervisory coaching behavior, employee satisfaction, and warehouse employee performance: A dyadic perspective in the distribution industry. Human Resource Development Quarterly 14: 435-458.

Ellinger AD, RG Hamlin and B R.S. (2008) Behavioural indicators of ineffective managerial coaching. Journal of European Industrial Training 32: 240.

Fatien P and K Otter (2015) Wearing Multiple Hats? Challenges for Managers-as-Coaches and Their Organizations. International Leadership Journal 7: 24-35.

Ferrar P. (2006) The paradox of manager as coach: Does being a manager inhibit effective coaching? Oxford-Brookes University Master of Arts in Coaching and Mentoring Practice, Oxford.

Gabriel AS, CM Moran and JB Gregory (2014) How can humanistic coaching affect employee wellbeing and performance? An application of self-determination theory. Coaching: An International Journal of Theory, Research and Practice 7: 56-73.

Gagne M and EL Deci (2005) Self-determination theory and work motivation. Journal of Organizational Behavior 26: 331-362.

Garvey B, P Stokes and D Megginson. (2014) Coaching and mentoring: Theory and practice, Sage, London.

Gioia DA, KG Corley and AL Hamilton (2013) Seeking qualitative rigor in inductive research notes on the Gioia methodology. Organizational Research Methods 16: 15-31. 
Gollan PJ, S Kalfa and Y Xu (2015) Strategic HRM and devolving HR to the line: Cochlear during the shift to lean manufacturing. Asia Pacific Journal of Human Resources 53: 144-162.

Gormley H and C van Nieuwerburgh (2014) Developing coaching cultures: a review of the literature. Coaching: An International Journal of Theory, Research and Practice 7: 90-101.

Gould-Williams JS (2016) Managers' motives for investing in HR practices and their implications for public service motivation: a theoretical perspective. International Journal of Manpower 37: 764-776.

Hamlin RG, AD Ellinger and RS Beattie (2006) Coaching at the heart of managerial effectiveness: a cross-cultural study of managerial behaviors. . Human Resource Development International 9: 305-331.

Hicks R and J McCracken (2011) Coaching as a Leadership Style. Physician Executive 37: 70-70-72.

Huang J-T and H-H Hsieh (2015) Supervisors as good coaches: influences of coaching on employees' in-role behaviors and proactive career behaviors. The International Journal of Human Resource Management 26: 42-58.

Hunt JM and JR Weintraub. (2016) The Coaching Manager: Developing Top Talent in Business, Sage Publications, Los Angeles, CA.

Jones RJ, SA Woods and YR Guillaume (2016) The effectiveness of workplace coaching: A metaanalysis of learning and performance outcomes from coaching. Journal of Occupational and Organizational Psychology 89: 249-277.

Karam EP, WL Gardner, DP Gullifor, et al. (2017) Authentic leadership and high-performance human resource practices: implications for work engagement. Research in personnel and human resources management, 103-153. Emerald Publishing Limited,

Kim S (2014) Assessing the Influence of Managerial Coaching on Employee Outcomes. Human Resource Development Quarterly 25: 59-85.

Kuvaas B, A Dysvik and R Buch (2014) Antecedents and employee outcomes of line managers' perceptions of enabling HR practices. Journal of Management Studies 51: 845-868.

Ladyshewsky RK and R Taplin (2018) The Interplay Between Organisational Learning Culture, The Manager as Coach, Self-Efficacy and Workload on Employee Work Engagement. International Journal of Evidence-Based Coaching and Mentoring 16: 3-19.

Lawrence P (2017) Managerial coaching - a literature review. International Journal of Evidence Based Coaching and Mentoring 15: 43-69.

Lin W-J, C-Y Lin and Y-H Chang (2017) The impact of coaching orientation on subordinate performance: the moderating effects of implicit person theory and LMX. Asia Pacific Journal of Human Resources 55: 86-105.

Longenecker CO (2010) Coaching for better results: key practices of high performance leaders. Industrial and Commercial Training 42: 32-40.

Matthews J (2010) Can line managers ever be effective coaches? Business Leadership Review 7: 1-10.

McCarthy G. (2014) Coaching and mentoring for business, Sage, London.

McCarthy G and J Ahrens. (2011) Challenges of the coaching manager. Future of work and organisations. 25th Australia New Zealand Academy of Management Conference 7-9 Dec 2011. Anzam, Wellington, New Zealand.

McCarthy G and J Milner (2013) Managerial coaching: challenges, opportunities and training. Journal of Management Development 32: 768-779.

McLean GN, B Yang, M-HC Kuo, et al. (2005) Development and initial validation of an instrument measuring managerial coaching skill. Human Resource Development Quarterly 16: 157-178.

Milner J, G McCarthy and T Milner (2018) Training for the coaching leader: how organizations can support managers. Journal of Management Development 37: 188-200.

Özduran A and C Tanova (2017) Coaching and employee organizational citizenship behaviours: The role of procedural justice climate. International Journal of Hospitality Management 60: 5866. 
Palmer S and A McDowall. (2010) The coaching relationship: putting people first. Routledge, Hove, England.

Pousa C, C Pousa, A Mathieu, et al. (2017) Managing frontline employee performance through coaching: does selling experience matter? International Journal of Bank Marketing 35: 220240.

Rapp-Ricciardi M, D Garcia and T Archer (2018) Personal attributes linked to empowerment that influence receptivity to coaching leadership. Coaching: An International Journal of Theory, Research and Practice 11: 30-45.

Rayner J and D Morgan (2017) An empirical study of 'green'workplace behaviours: ability, motivation and opportunity. Asia Pacific Journal of Human Resources Version of record online 27 April 2017 DOI 10.1111/1744-7941.12151.

Rock D and R Donde (2008) Driving organizational change with internal coaching programs: Part one. Industrial and Commercial Training 40: 10-18.

Rosha A (2014) External and internal conditions to promote coaching in organisation. KSI Transactions on KNOWLEDGE SOCIETY 7: 30-37.

Ryan RM and EL Deci (2000) Self-determination theory and the facilitation of intrinsic motivation, social development and well-being. American Psychologist 55: 68-78.

Saldaña J. (2009) The coding manual for qualitative researchers, Sage, London.

Schalk M and J Landeta (2017) Internal versus external executive coaching. Coaching: An International Journal of Theory, Research and Practice: 1-17.

Spence GB and EL Deci (2013) Self-determination theory within coaching contexts: Supporting motives and goals that promote optimal functioning and well-being. Beyond Goals: Effective Strategies for Coaching and Mentoring: 85-108.

Stober DR (2008) Making it stick: coaching as a tool for organizational change. Coaching: An International Journal of Theory, Research and Practice 1: 71-80.

Trullen J, L Stirpe, J Bonache, et al. (2016) The HR department's contribution to line managers' effective implementation of HR practices. Human Resource Management Journal 26: 449470.

Turner C and G McCarthy (2015) Coachable Moments: Identifying Factors that Influence Managers to take Advantage of Coachable Moments in Day-to-Day Management. International Journal of Evidence-Based Coaching and Mentoring 13: 1-14.

Turner PS. (2010) Aligning organisational coaching with leadership behaviour. Business School. Birmingham City University, Birminhgam, England.

Van Waeyenberg T and A Decramer (2018) Line managers' AMO to manage employees' performance: the route to effective and satisfying performance management. The International Journal of Human Resource Management: 1-22.

Wakkee I, T Elfring and S Monaghan (2010) Creating entrepreneurial employees in traditional service sectors. International Entrepreneurship and Management Journal 6: 1-21.

Wang J (2011) Understanding managerial effectiveness: a Chinese perspective. Journal of European Industrial Training 35: 6-23.

Wheeler $L$ (2011) How does the adoption of coaching behaviours by line managers contribute to the achievement of organisational goals? International Journal of Evidence Based Coaching and Mentoring 9: 1-15.

Whitmore J. (2009) Coaching for performance, Nicholas Brealey, London. 


\section{Appendix Managerial Coaching Survey Questions}

1. How many people are employed by your organisation?

2. Broadly speaking, what is the core business of your organisation?

3. How would you describe what a manager does when he/she coaches?

4. Do you yourself do any coaching?

5. Whom do you coach?

6. Which of the following do you coach?

7. How often do you coach your employees?

8. What coaching behaviours do you use? Please tick all which apply.

9. For what purposes do you as a manager use coaching? Please tick all which apply.

10. Do you see any differences between a manager coaching and a manager using other leadership styles?

11. As a manager, have you experienced any benefits from adopting a coaching style?

12. Have you observed any benefits for the people you coach?

13. Do you think there may be any other benefits from managerial coaching in general?

14. Have you experienced any difficulties with coaching as a manager?

15. Have you experienced any of the following difficulties with coaching as a manager?

16. What other difficulties, if any, do you think might arise with managerial coaching in general?

17. Please describe a critical incident (positive or negative) from your own experience as a coaching manager

18. Have you had training in coaching?

19. What training have you had in coaching?

20. On a scale of $1-10$, where 1 is extremely difficult and 10 is extremely easy, how easy do you find it to use your coaching skills as a manager?

21. Do you get any support from your company in regard to coaching as a manager?

22. What further support, if any, from your own company would you like to assist you with coaching as a manager?

23. Would you describe your company's culture as a coaching culture?

24. Are there any other comments you would like to make about being a coaching manager? 